\title{
Contract Farming in the Morocco Cereal Sector: Contract Clauses, Ambiguity, and Opportunism
}

\author{
Bouichou El Houssain ${ }^{1,2, ~ *, ~ A z i z ~ F a d l a o u i ~}{ }^{1}$, Khalil Allali ${ }^{2,3}$, Radouan Arrach ${ }^{4}$ \\ ${ }^{1}$ Regional Agricultural Research Center, National Institute for Agricultural Research (INRA), Meknes, Morocco \\ ${ }^{2}$ Department of Economic and Social Sciences Applied to Agriculture, Agronomic and Veterinary Institute Hassan II, Rabat, Morocco \\ ${ }^{3}$ Department of Rural Economy, National School of Agriculture, Meknes, Morocco \\ ${ }^{4}$ Strategy and Statistics Directorate, Ministry of Agriculture, Fisheries, Rural Development, Water and Forests, Rabat, Morocco
}

Email address:

bouichouelhoussain@yahoo.fr (B. El Houssain)

${ }^{*}$ Corresponding author

\section{To cite this article:}

Bouichou El Houssain, Aziz Fadlaoui, Khalil Allali, Radouan Arrach. Contract Farming in the Morocco Cereal Sector: Contract Clauses, Ambiguity, and Opportunism. International Journal of Agricultural Economics. Vol. 4, No. 5, 2019, pp. 245-253.

doi: $10.11648 /$ j.jjae.20190405.17

Received: September 27, 2019; Accepted: October 15, 2019; Published: October 24, 2019

\begin{abstract}
Our main aim was to analyze of the various types of contractual clauses framework of Agricultural Aggregation Projects (AAP) in the cereal sector in Morocco. We used the data from the content of the contracts and by individual interviews with key actors complicated in the process of implementation of the aggregation projects of cereals. The results reveal that only eight Agricultural Aggregation Project, out of 119, received the certificate of aggregation. This is reflecting the fact that, the implementation of this model of vertical coordination was underway. In addition, the analysis of the contract-farming data for clauses has shown us 5 important clauses categories: production (quantity and quality) and payment methods; agricultural extension systems; inputs supply; management of risks; and dispute resolution mechanisms. These findings highlight the value added to the contractual clauses and the need to strengthen the visibility and role of the contract farming as a framework to accompany the investments of "The Green Morocco Plan", in particular with regard to agricultural aggregation projects. We also show that the contract participation reduces the transaction costs in aggregation system, reduction in the number of intermediaries and ensure the link between the producers and markets. The study concludes that, despite enactment of laws on farm aggregation, contract smallholders remain vulnerable to opportunist behavior. It suggests that the contract clauses must be accompanied by commensurate controls and Involving farmers in negotiating contract terms to ensure 'win-win' outcomes for Aggregator (AG) and Aggregated (Ag).
\end{abstract}

Keywords: Cereal Aggregation Project, Transaction Costs, Contractual Clauses, Contract Farming, Vertical Coordination

\section{Introduction}

Agriculture is a strategic sector that is crucial to the Moroccan economy. This sector accounts for 14 per cent of Moroccan's gross domestic product (GDP) and provides employment to $38 \%$ of the countries workforce [1]. What is more, this sector plays a significant socio-economic role as $75 \%$ of the 14 million rural inhabitants depend on revenues from the agricultural sector [2].

In addition, the agricultural sector's contributes to both poverty alleviation and economic growth [3]. However, it has been an important challenge that must be raised adequately addressed. Indeed, under the influence of global changes characterized mainly by climatic changes, major water stress, rising prices of farm inputs, and decline in food security. In this regard, Morocco has felt the need to engage a new strategy to guard against the market requirements, and addressing major impediments in agriculture and rural development [1,2].

In fact, a new strategy was launched in 2008, called "Green Morocco Plan". It is aimed to make agriculture the main engine of growth of the agricultural sector. This strategy is based on a new model of vertical coordination "Aggregation", which will help enable the regulation 
between the productive upstream and the commercial downstream, in order to fostering partnerships with various stakeholders from the private and public in the agricultural sector [4]. It has been reported by [2, 4] that, the aggregation is to further improve the production (quality, quantity) and to strengthen the small farms, with the aim to steadily intensification the production of cereals, strengthen the vertical coordination in the agri-food chains, improve value added in the sector and remedy distributional distortions.

The aggregation, announced in 2012 , is a state strategy to develop agriculture in a global economy characterized by food insecurity, and trade liberalization and climate change. Within the framework of this project, the ministry of agriculture implements a rigorous and comprehensive human and financial resources accountability system consistent with the AAP [4]. These measures are accompanied by monitoring, examination and surveillance measures. In that connection, the aggregation constitutes an appropriate solution to get around the issue of small farms and to face the challenges related to the lack of organization in the agricultural sector [4]. Moreover, in Morocco a large portion (70 \%) of farmers in Morocco have less than 5 hectares. These small-scale farmers have insufficient managerial skills and do not have the technical and financial means for developing their production systems [1]. In line with the strategy introduced, and in order to cope with the constraints hindering the development of the cereals sector, a contractprogram, has been launched for the period 2008-2020 has been launched. This contract-program aims to specify the deployment program for cereal development strategy of Morocco on one hand, and pursued a policy of contract farming, between the state, representative professions and the private sector on the other hand [1].

A major factor in aggregation choice was how to alleviate the problem of agricultural land fragmentation [3]. The major advantage of partnership is that they provide strong incentives for all actors involved in contractual arrangements to minimize transaction costs (loss of working hours, problem of transporting agricultural implements and products [5-7].

Under the terms of the contract, sellers presumed to be knowledgeable regarding the implications of contract clauses. Instead, they are not knowledgeable of the terms of the contract, and often to have not even read them [8]. The contract must remain a mechanism that the contracting parties may use only when all the other stakeholders shall ensure that adequate and effective means exist to prevent the ambiguity of contract. Therefore, in the interest of clarity of contract clauses, it is appropriate to harmonize the agreement on transaction and increasing the quality of law [9].

Hence this study was designed to identify the Agricultural Aggregation Projects (AAP) in the main cereal crops, and analyze the components of contractual clauses. Thus, it involves analyzing data collection on provisions of the aggregation contracts and the provisions of the agreements. Aggregation projects are selected for this study because it is a strategy was intended to motivate smallholder farmers to contract farming. It was established between the State and representative professions, that is the Legumes and the National Federation of Flour millers, National Association of the Producers of Cereals and Legumes, and National Federation of Traders of Cereals.

Under aggregation contract, farmer and firm make advance agreements and clauses concerning the management of contract farming. We discuss five types of contractual clauses and their implications for farmers' returns and risks: 1) production and payment methods; 2) agricultural extension systems; 3) inputs supply; 4) management of risks; and 5) dispute resolution mechanisms.

\section{Literature Review}

\subsection{Concept of Contract Farming}

Contract farming is a sales contract between an agricultural producer and industrial promoter, which aims to securing the supply and provides the farmer with technical and financial. Many agricultural policies and governments support contract farming as part of agricultural development [10]. As such, in principle contract farming is a necessary condition to increase agricultural productivity, economic development, and food security. In this context, membership in contract farming is often linked with increases in food security, improvements in farm income, and reducing rural poverty [11]. CF can improve farmers' access to new agricultural technologies, input financing, and long-term improve the overall performance of the farm [12]. Many researchers have addressed the importance of $\mathrm{CF}$, based on empirical studies from around the world in general and especially in developing countries context, that discover positive productivity and value-added of contract-farming for smallholder farmers — see [10, 13, 14].

It helps farmers to find a market for their products with reasonable price and often supply inputs (seeds, fertilizers and agrochemicals), technical assistance, agricultural extension services, training and supervision [15-17] promote access to financing and credit [18, 19]. Nevertheless, the evidence that does exist suggests the local governments, agricultural professional organizations, private local firms, agricultural companies, financial institutions etc. have been involved in these contract farming schemes [20]. Contract farming plays a significant role in the coordination among the various actors that makes such a high degree in the integration of smallholders in agribusiness chains [21]. The FAO also pays significant attention to the importance and the role played by $\mathrm{CF}$ in embedded services, credit arrangements, payment systems and price-setting mechanisms [22].

\subsection{Cereal Sector in Morocco}

According to Ministry of Agriculture and Maritime Fisheries, the cereal sectors represent one of the largest subsegments in Morocco's agriculture sector. In fact, this sector has shown the greatest growths that occupy the largest proportion of the agricultural surface areas (75\% SAU). 
However, represent only 10 to $15 \%$ of agricultural revenues and only 5 to $10 \%$ of employment in the sector [23].

Despite the late offset of the rains, about 10.2 million tons of wheat was harvested in 2018 (2.9m tons of barley, $2.4 \mathrm{~m}$ tons of durum and $4.9 \mathrm{~m}$ tons of wheat), slightly above the previous year's harvest and 22 percent above the five-year average $11.2 \mathrm{~m}$ tons at 10.5 million tons [24]. The 2018 cereal production exceeded the five-year average by almost 25 percent, but remained below the record-breaking cereal output of 11.8 million tons gathered in 2015. The 10.2 million tons of cereals in 2017 was the highest value recorded in the last 50 years for which data are available [25].

Cereal import in the $2017 / 18$ was achieved at 6.5 million tons, 8 percent less than in $2016 / 17$. The country relies heavily on wheat imports to cover its consumption needs. The imports of cereals were around 42 million tons during the years 2000-08, and rose to 54 million tons during the period 2009-2017 (Figure 1). As in other Maghreb countries, the consumption of cereal in Morocco has relied heavily on imports of cereal grains, especially for major cereals including wheat and barley. Cereal imports has doubled during the past decade, from 3.6 million tons in 2003 to 7.5 million tons in 2016. As a result, the large proportion of cereal consumed in the country comes from imports, but relatively stable in the last five years, or 6.5tons, in 2017 (Figure 1). The comparison, by quantity, of the cereal import of the start of a new strategy in agriculture launched in 2008 and end of 2017 recorded an overall growth rate of around $18 \%$. This increase is particularly important from an economic perspective; it will continue to put a heavy strain on the balance of trade. Figure 1 also shows the production quantities over the past 18 years. The major cereals (Wheat, Barley, corn) ranks first in cereal production, with a national output reaching a record level of 11.5 million tons in 2014 . This was an increase of 4.58 million tons over the previous 10-year average. he production has significantly increased significantly increased after 2008 (Green Morocco Plan), exceeding the average cereal production of the eight years before the launch of the PMV. In effect, the average production rate for all of 2000 to 2007 was 5.9 million tons, compared with an average rate of 8.3 in 2008 to 2017, an increase of $16 \%$. Statistics show that cereals' productivity has never been as high as in 2017 (22.9 quintals/ha). However, further to the difficult weather conditions in much of the country, cereals production it has been significantly reduced in the 2006-2007 (2.4 million tons) crop year. It was the lowest in 15 years. Moreover, this production characterized in recent years by fluctuations in production depending on factors such as the climatic conditions.

The country's cereal strategy focuses on reduction in the area dedicated to cereal cultivation, but to simultaneously increase yields so that net cereal production would rise of the cereal area as well as on mechanization crop management and input optimization. In fact, the cereal land area diminished by 723 thousand hectares compared with 2007 . When comparing the 2017 values with the 2000-2017 average, the discrepancy between the increase in harvested production $(+2.9 \%)$ and the area cultivated with cereals ($1.6 \%$ ) suggests a significant improvement in yield. These crops were cultivated on less than $38 \%$ of the favorable rainfed zones; the remainder was planted in the unfavorable regions. The barley remains the most cultivated (40\%), the mountainous zones or the oases $(22 \%)$.

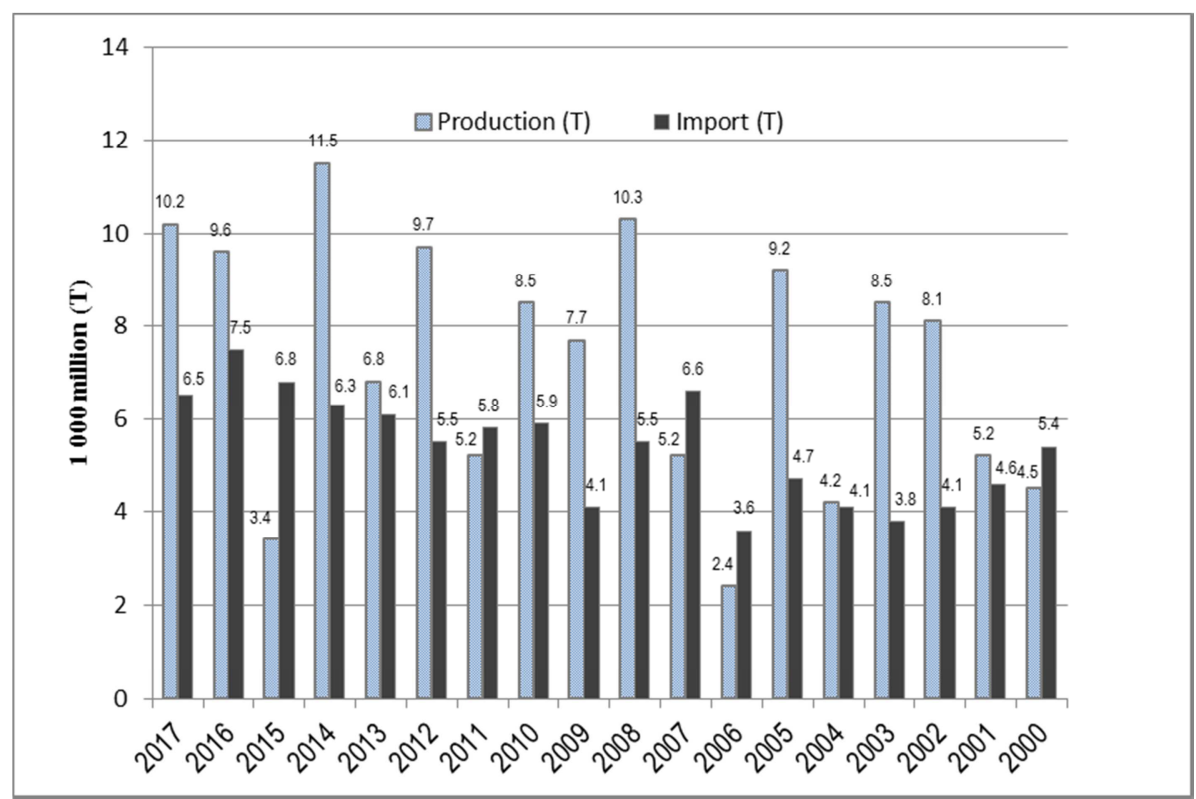

Figures are calculated based on Morocco's National Inter-Professional Office for Cereals and Legumes (ONICL). (2018).

Figure 1. Cereal (Wheat, Barley, corn) production and import in Morocco 2000-2018.

\subsection{Objectives and Principles of Aggregation Concept}

Agriculture can be considered one of the businesses with several risks. In most cases, smallholder farmers are challenged on their daily basis with the fluctuation of yields, 
an ever-changing of product prices, and other consequences that affect their economic returns. Therefore, it is obligatory to increasingly move towards new techniques of meeting the needs. In order to cope with the constraints hindering the development of the cereals sector, a contract-program, covering the period 2009-2020. The implementation of the contract-program began to revive the cereal sector. This strategy was intended to motivate smallholder farmers to contribute in an aggregation projects. It was established between the State and representative professions, that is the National Association of the Producers of Cereals and Legumes, the National Federation of Traders of Cereals and Legumes and the National Federation of Flour millers. The latter determine the objectives to be reached, the investments to be mobilized and the commitments of the signatory parties. The contract-program specifies as an example the objective to reach by 2020 of a level of 7 million tons of cereal production in average year [26]. One of the general recommendations in order to cope with the agricultural risks is aggregation, in which farmers are provided to have an access to many tools (insurance and hedging) that can diminish their farm-level risks. Aggregation is therefore one of the means to lessen and to manage the risks of the agricultural activity and its market risks. Contract farming (CF) has long been practiced but is since the launch of Green Plan of Morocco (PMV) it has regained an important interest with noticeable diversification in structures and involved actors [27].

\section{Empirical Illustration}

\subsection{Data}

This research orientation aims at improving the acceptability of the project of aggregation on cereals by agricultural producers. It consists in analyzing the acts of regulation and contractual clauses. It also involves analyzing data collection on provisions of the aggregation contracts and the provisions of the agreements. For this purpose, individual interviews were conducted with key actors involved in the process of implementation of the aggregation projects of cereals. Methods mobilized were include, among other things, the Knowledge, Attitude and Practice approach; and the Strengths, Weaknesses, Opportunities and Threats approach. Given the specific context of the study, it is imperative to take a complementary approach. The first requirement for our approach is the collection, examination and analysis of secondary data. The patter focused on the agreements and contract for cereal aggregation project launched at national scale, several data sources were used. During the second phase, interviews were conducted with key actors involved in the process of implanting cereal aggregation projects. The third stage was dedicated to the analysis and synthesis of the investigations.

The data we use to analyze the current level of vertical coordination in the field of cereal sector can get come from an investigation conducted in Morocco in the crop year. As part of in aggregation «one of the foundations of the Green Morocco Plan (PMV) is an innovative model of farmer's organization around private actors or professional organizations ", the survey team collected data on 7 projects of the AAP for cereals having received the certificate of aggregation amounts. The data were collected to analyze the acts of regulation and contractual clauses in contract farming. We keep our discussion of the general survey short to focus on the contracts themselves and on the determinants of contractual clauses. The regional distribution reveals that the 7 identified AAP relate to 4 areas with a concentration on the level of the areas of Chaouia-Ouardigha, the Greater Casablanca, Marrakech-Tensift-El Haouz, Fes-Boulemane, and Doukkala-Abda. These four areas involve all Agricultural Aggregation Project, i.e. 100\%.

\subsection{Results and Discussion}

These investigations sensed the implementation of 119 Agricultural Aggregation Project (AAP) in the main cereal crops. The number of the AAP for cereals having received the certificate of aggregation amounts to 8 . The analysis of the status of $\mathrm{AG}$ shows a diversity of the types with a predominance of the companies followed by the cooperatives.

This distribution also shows a certain concentration of the APP according to areas. The checked projects concern the centralized model. The aggregation models aim to link the farms to progress and comfort formally on the mechanism of double contracting between the State and the aggregator (AG), on the one hand, and between the aggregator AG and the farmers being aggregated (Ag) on the other hand.

The regional distribution reveals that the 7 identified AAP relate to 4 areas with a concentration on the level of the areas of Chaouia-Ouardigha, the Greater Casablanca, MarrakechTensift-El Haouz, Fes-Boulemane, and Doukkala-Abda. These four areas involve all Agricultural Aggregation Project, i.e. $100 \%$ (Table 1). Consistent with the Rainfed Agriculture Development Project (RADP), table 1 also shows that the vast majority - almost $70 \%$ - of the projects in our data are rainfed crops. In the cereal sector rainfed crops predominate, which remains a cause for concern given the vagaries of the climate and rainfall deficit experienced in recent years. Around $57 \%$ of contract farmers are member of a farmers' organization; which reflects the fact that organizing themselves in small groups is an important part of the contract farming. Lastly, the analysis of the status of AG shows a diversity of the types with a predominance of the companies $(57 \%)$ followed by the co-operatives $(28 \%)$ (Table 1). These ten projects mobilized an investment of $594.61 \mathrm{M}$. Dh; i.e. $6.31 \%$ of the total investment allocated to the AAP associated with the vegetable productions. When considering the whole group of AAP (all productions included) this percentage is only $3.71 \%$. The fund is invested mainly in installation of processing units, storage and/or valorization according to the type of projects, farm equipment and agricultural machinery. In terms of surface and number of $\mathrm{Ag}$, these projects extend on 61,750 ha, either 
nearly $38 \%$ to the incorporated total area, and relate to 6,357

$\mathrm{Ag}$, or $37 \%$ of the total staff number of $\mathrm{Ag}$ of the AAP

relating to crop productions.

Table 1. Main elements of the agreement on contract farming of cereals.

\begin{tabular}{llll}
\hline Characteristics & Detailed modalities & Number of projects involved & Percent \\
\hline \multirow{3}{*}{ Region and geographical location of the projects } & Chaouia-Ouardigha & 5 & 62,5 \\
& Grande Casablanca & 1 & 12,5 \\
& Fes-Boulemane & 1 & 12,5 \\
& Doukkala-Abda & 1 & 12,5 \\
Purpose of production & Cereal crops (grains) & 5 & 62,5 \\
\multirow{2}{*}{ Systems and crop management } & Wheat seeds & 3 & 37,5 \\
& Rainfed & 6 & 75 \\
Status of AG & Irrigated & 1 & 15 \\
& Compagnies & 4 & 57 \\
Farmers' Organisation & Cooperatives & 2 & 28,5 \\
& Economic interest groups (GIE) & 1 & 14,5 \\
& Agricultural cooperatives & 57 \\
\end{tabular}

Table 2. Summary of commitments and modalities associated with the supply of inputs from cereal aggregation contracts.

\begin{tabular}{|c|c|c|c|}
\hline \multirow{2}{*}{ Commitment/terms of the contract } & \multicolumn{3}{|c|}{ Number of projects concerned by various supply of inputs } \\
\hline & Seeds & Fertilizers & Pesticides \\
\hline \multicolumn{4}{|c|}{ Agreement outlines the details of exclusivity of sales } \\
\hline Specified & 1 & 1 & 1 \\
\hline Unspecified & 7 & 7 & 7 \\
\hline \multicolumn{4}{|c|}{ Actors involved in the choice of input purchase } \\
\hline Agreement with the aggregated & 6 & 6 & 6 \\
\hline Aggregator & 2 & 2 & 2 \\
\hline \multicolumn{4}{|c|}{ Information concerning the delivery schedule } \\
\hline Specified & 6 & 6 & 6 \\
\hline Unspecified & 2 & 2 & 2 \\
\hline \multicolumn{4}{|c|}{ Information concerning the place of delivery } \\
\hline Specified & 6 & 6 & 6 \\
\hline Unspecified & 2 & 2 & 2 \\
\hline \multicolumn{4}{|c|}{ Clauses relating to the price fixing of inputs } \\
\hline Specified & 6 & 6 & 6 \\
\hline Unspecified & 2 & 2 & 2 \\
\hline \multicolumn{4}{|c|}{ Terms of the contract as to the payment options } \\
\hline Payment on delivery of the inputs & 2 & 1 & - \\
\hline Payment on delivery of the production & 6 & 7 & 7 \\
\hline
\end{tabular}

Table 3. Principal commitments in terms of quantities and quality of production.

\begin{tabular}{llc}
\hline \multirow{2}{*}{ Contractual clauses relating to the quantities and quality of production } & \multicolumn{2}{c}{ Contract design attributes as a percentage of the analyzed projects } \\
\cline { 3 - 3 } & Specified & Unspecified \\
\hline Reference parcel area devoted to the contract crop. & 100 & - \\
Parcel area (Ha) & 50 & 50 \\
Location and delimitation of the site & 75 & 15 \\
Prohibition of transfer the right to exploitation. & 75 & - \\
Prohibition against assuming the commitments with another third. & 100 & - \\
Authorisation for inspection. & & 15 \\
Terms of the quality of production & 25 & 75 \\
Ensure the quality of production & & \\
Specification of the quality standards &
\end{tabular}

Table 4. Agreement on delivery prices and methods of payment.

\begin{tabular}{ll}
\hline Commitments/ Methods of payment & Percentage in terms of the total number of projects analyzed \\
\hline Terms and conditions of the setting of sales prices & \\
\hline Grain production & 16 \\
Agreement based on reference market price & 34 \\
Agreement based on reference price & 50 \\
Agreement based on reference price \& average market price & 50 \\
Seed production & 50 \\
Agreement based on reference price of seeds & \\
Agreement based on reference market price of seeds & \\
Payment method &
\end{tabular}




\begin{tabular}{ll}
\hline Commitments/ Methods of payment & Percentage in terms of the total number of projects analyzed \\
\hline Terms and conditions of the setting of sales prices & \\
\hline Specified & 100 \\
Unspecified & \\
Payment term & 62 \\
At the latest 15 days after the delivery. & 12 \\
At the latest 21 days after the delivery. & 26 \\
Unspecified & 25 \\
Quality premium & 75 \\
t to 5\% & \\
Unspecified & 25 \\
Interest rate for production advance & 75 \\
mentioned and specified & Unspecified
\end{tabular}

Table 5. Presents a summary of the contractual provisions related to multi-risk insurance.

\begin{tabular}{ll}
\hline & As a percentage of the analyzed projects \\
\hline Obligation to introduce a system of compulsory insurance. & 71 \\
Mentioned and specified & 29 \\
Unspecified & \\
Terms stating different types of insurance & 70 \\
climatic risks & 57 \\
Fire insurance & 57 \\
\hline
\end{tabular}

Table 2 shows who provides the various inputs in the contracts in our data. Seeds, phytosanitary products and chemical fertilizers are provided by the aggregator. Most of the contracts stipulate that the aggregators are engaged to technically support the aggregated farmers and to ensure monitoring of the farming practices application following a concentered program between the two parts of the contract. Looking at the clauses under contract in these data truly embodies the variety in which the Inputs supply. For these contracts, the aggregator has ownership of the goods; control may be obtained by ownership of assets, or through rights or contracts that give the controlling party the capacity to control. However, the problem is that producers are attracted to use inputs supplied under contract for purposes other than those for which they were intended. Thus sometimes they prefer to use the inputs on their other crops or even to sell them. The role of the state in the contract can be very important, may act as a liaison between the aggregator and aggregated and benefit to build farmers' confidence on the contract relationship. This is consistent with findings by [20, $21,28]$, who examined a large number of agricultural production contracts. The authors find that a production contract usually specifies in detail the inputs supply to be supplied by the contractor, the quantity and quantity of the particular commodity involved, the productions methods to be used, and the outline what technical support needs may be required to support either enhanced productivity.

Inputs (farms equipment) are highly subsidized in Morocco, It may help the company interact with the farmers, helping in access to agriculture inputs and technologies. The State he plays an enabling role in the formation and execution of the contract relationships,, helping in discussions regarding the elements of the contract. It also gives subsidies for farm machinery, up to 50 per cent. Contractual stipulations relating to the price and subject the prices, terms and places of delivery, vary according to the type of contract and the types of inputs. As far as the terms of terms of payment, typically have a term of several years. With regard to technical assistance envisaged in contracts, is defined as transfer, adaptation, mobilization, and utilization of input, technical advice and quality control matters. These terms are usually used for crops that quality standards or require specific inputs, where farmers find it difficult to supply the agricultural inputs. Therefore, in the contract farming the farmer supplies land and labor while the contractor supplies all the inputs. Within those contractual terms, clauses illustrate how contract farming arrangements may improve competency in terms of farming and management practices. In addition, there is a relatively strong level of competency in terms of farming and management practices. Moreover, most contracts stipulate that the aggregator provides farmers with assistance, at both technical, organizational and management level, in establishing productive farming. This statement, is not in line with the confirmation relied upon and commented by [29]. They conclude that in contract farming there is an information gap in terms of demand and prices. Farmers do not have the bargaining power to push demand and set the selling prices that firms offer.

A. Quantities, quality and terms of payment

Table 3 shows the principal commitments in terms of quantities and quality of production. On the basis of the contracts analyzed in this study, contracts include details, inter alia, of the exact location where the cereal is produced and the area of the parcel concerned. Additionally, they include specific requirements regarding using of the property in the contracts. Requirements are not limited to reference area; $75 \%$ of these contracts used contained provisions linking prohibition of transfer the right to exploitation and prohibition against assuming the commitments with another third. On the other hand, in addition to its potential limitations, to the need to ensure sufficient quality, and 
concerns about product quality often significantly affect the structure of these relationships. Consistent quality standards for commodities are one of the main requirements of cereal value chains. In order to ensure production of such a high quality that the long-term viability of the farming, stakeholders was largely used contract terms to ensure the quality of production. Besides, the study revealed certain differences between contracts in the aggregation project. In fact, only $25 \%$ of these contracts indicates the specifications of the quality standards (table 3). However, the nonstandardized commodity quality from heterogeneous production conditions is a significant and expensive problem for aggregators (AG). For this reason, aggregators often impose standards on crops to ensure a homogenous quality of crops, and they supervise production to control and maintain that quality. In addition, aggregators often provide technical services to achieve the consistent quality. Data on the quantity, particularly commitments such as scheduling, delivery timing, and volume purchased by the contractor are only described broadly, if at all. While yields are expressed on a per-hectare basis. Quantity considerations are omitted to focus on quality incentives. Almost all contract contain exclusivity clauses. As for the terms of payment, our findings are consistent with the literature. $[21,28,30]$ indicating the contractual clauses usually include a fixed price for the products and payment time. According to these authors, the terms of the contract also entails a minimum quality requirements, and commitment to fulfilling contract requirements by both the farmers and the firms.

B. Elements of the fixing of purchase prices and trading conditions

In Table 4, we outline the core elements of the contractual arrangements between aggregators (AG) and aggregated (Ag). For the Crops production, we found three types of price formation. The first agreement based on reference market price; we find that approximately $16 \%$ of agreement based on reference market price. In doing so, information submitted by third parties and all other available information shall be taken into account. The second aspect is the use of reference price (34\%), based on concertation between the actors; it marks an original approach from the transparency, accountability, and governance points of view. And third, half of the agreement based on both a reference price and average market price. Accordingly, price setting could bring some benefits, such as risk reduction, both for farmers and the buyer firm. Table 4 also provides a comparison of price setting between the grain production and seed production. In general, the price settings are the same in both productions. However, in the seed production, pricing strategies tend to vary depending on whether a company the implication level of technical assistance. It becomes clear that the written contracts have weaknesses in terms of payment term and payment method because they lack transparency and details. For example, the contracts only state the payment terms and the repayment deadlines, but not including any interest on late payment, payment deadlines do not automatically commitment respect of payment. However, payments to the growers are made throughout the year; one for quantity and another from the bonus received from quality. Furthermore, the contract obligates the parties to sell and buy respectively the entire contracted quantity at the pre-agreed price. However, the gap of bonus per quantity delivered for the farmers is no more than $5 \%$ compared with the quality standards. The results obtained for the quality of contractual terms of farmers suggest that some $25 \%$ of the aggregation projects are the subject of quality premium. However, the exact price determination process is not specified in the contract and is difficult for farmers to understand. Quality grading, which determines any price premium, is performed by the Contractor. Overall, the aggregation project establishes a fixed price that the aggregated will receive as agricultural producers. The seeds aggregation project has connected a huge number of small farmers in the contract farming framework. Higher productivity owing to better quality seeds and better price for the crops because of the elimination of intermediaries is the key reason behind the success. Furthermore, aggregation may assure producers of ready markets at attractive or reasonable prices, significantly reduces the probability of experiencing price shocks, this result indicates that aggregation, thereby minimizing price risks. In contrast, if the open-market price crosses the agreed price, then also the farmer loses as, in very few cases, the contract allows farmers to sell in the open market. This accord with earlier observations that terms of the agreements are shown typically in two dimensions [31]. At one extreme, the prices are fixed and the contractor exercises constant and rigorous control over all aspects of production (crop management, production practices, identify the varieties of crops to be cultivated, standardization of the crop through and the quality of the final products). At the other, extreme company pays the market price on delivery and exercises little control over production (during the harvest).

\section{Management and sharing of risks}

Table 5 presents a summary of the contractual provisions related to multi-risk insurance. To some extent, they do not cover only against climatic or natural disasters but also against fire risks. In fact, the cover includes yield loss caused by natural perils, such as fire, flood, and lightning. In contrast, the innovative insurance product, such as indexbased insurance, remains underserviced in aggregation system. We found that underwrites insurance are well focused on the key risk areas. Of all the cereal producers included in the aggregation projects, $71 \%$ are insured (table 5). Penetration of climatic risks insurance exceeds 70 percent in aggregation projects but is still much lower than would be expected given their level of importance. As regards fire insurance, the $57 \%$ of the producers are insured. Under climate insurance, the indemnity payout is based on a verifiable and transparent index (such as the level of rainfall, the aggregate crop yield in a given area). Although the insurance plays a prominent role in agricultural contracts, farmers are presumed to be relatively uninformed regarding the provisions of multi-risk insurance, and often to have not even read them. Anyway, It is consistent state policy to allow 
aid up to $90 \%$ of the cost of insurance. The measure was adopted to encourage farmers to take part in agricultural insurance. For farmers, the amount of direct support they receive per hectare varies from one zone to another, especially in terms of apparent evolution of risk. This grid ranges from $600 \mathrm{dh} / \mathrm{ha}$ to $4350 \mathrm{dh} / \mathrm{ha}$. In certain contracts, the growers are forced to insure against fire, wind- storm, drought, and excess rain. Finally, Mamda is today the first agricultural insurer in the Moroccan market (the $100 \%$ for insured farms), this insurance company has developed a network of more than a hundred agricultural experts and advanced in cutting-edge information systems (automated payments satellite monitoring, geolocation, etc.). This strategy has increased the number of participants in the agricultural insurance. This is confirmed on the poultry sector when [31] states that terms related to insurance in the contract farming is a important advantage for management and sharing of risks.

\section{Mediation, agree dispute resolution}

Regarding settlement of disputes, they must be settled peacefully and in accordance with law 04/12 related to the agricultural aggregation. Such a dispute may, nevertheless, be submitted to adjudication by agreement. Hence, the dispute resolution clauses specify how the parties will manage disagreements.

In the first place the contracting parties would rather settle the dispute amicably. In case it is completely impossible the parties have the right to bring a claim before a collegiate body. Secondly, a competent body is usually a public or private body, designated by the chamber of agriculture, which presents the necessary guarantees for impartiality and availability of technical expertise for carrying out a verification of the dispute with regard to its compliance with the contractual clauses. This committee is a collegiate body backed and supervised by the Chamber of Agriculture and inter profession. The committee will be required to prepare and deliver all meeting notes within thirty (30) working days. The minutes, concerning claims which have not been settled, will be subject to negotiations in order to reach an amicable settlement. In the event that mediation and intermediation were failed, the dispute will then be resolved in accordance with the applicable rules (law 04/12), the parties to a dispute shall make every effort to resolve it amicably in accordance with the relevant terms and conditions of contract. Thirdly, if no amicable agreement is reached, the trade court is the sole competent court to decide on any litigation resulting from the non-compliance of the contractual conditions. However, the nature of alternative dispute resolution procedure differs from one country to another. For example, according to the [32], on contract farming legislation is considered relatively strict in India. In fact, disputes on contract farming agreement are referred to the prescribed authority, who would resolve the dispute within 30 days after giving the parties a reasonable opportunity of being heard. The decision made by the authority is enforceable as it is equivalent to the decree of the civil court.

\section{Summary and Conclusions}

Summarizing the results of this study, we outline the main findings. First, the results reveal that models of agro food aggregation constitute the central concept recommended for the first pillar of the Green Morocco Plan. Thus, one of the outstanding contributions of the PMV is to seek to extend, organize, regulate and encourage through subsidies the development of CA in Morocco through the models of aggregation. Second, after analyzing vertical coordination in the cereal sector, the results show that the projects consulted fit in with the (centralized model) through a public-private partnership, leading to increased access to inputs, technology, and improvements in quality and productivity of farms. However, this is not the case for production risks. This result could be an indication that the extension services awarded by this model is effective, whereas the technical assistance provided through a centralized model is often ineffective for coping with production risks.

Third, using the contract contents, we find that most of the contract clauses specify that the aggregates have the duty to deliver the production respecting the agreed quality standards. Our findings can therefore serve as a signal to policy-makers that managing contract clauses are vital prerequisite of value creation for farmers and their partners. Looking at the results of the aggregation project implemented to reinforcement of the vertical links in the supply chain, we can verify that aggregated farms are more are more organized and professional and frequently managed by highly educated farmers. Fourth, CF analysis suggests that contract participation is would make it possible to draw economic benefits for the Ag's, the AG's and the State by achieving economies of scale and, possibly, the reduction of the costs of transactions. In addition to sharing the risks of production and marketing between the stakeholders, aggregation generates several substantial advantages.

In conclusion, this preliminary analysis of the cereals contracts practiced in Morocco, there are admittedly significant efforts to formalize and regulate contractual relations. Nevertheless, the forms of presentation of contracts consulted suffer from several shortcomings and insufficiency. Several clauses are missing or are particularly vague in the areas of guarantees, reduction, quality bonuses..., knowing that he use of specialized bodies for the drafting of contracts is rarely carried out, significant efforts remain of their content and the standardization of their structure which would take into account the guidelines of the law on aggregation.

\section{References}

[1] Ministère de l'Agriculture, de la Pêche Maritime, du Développement Rural et des Eaux et Forêts, 2019. «L'AGRICULTURE EN CHIFFRES 2018».

[2] Ministère de l'Economie et des Finances, Direction des Études et des Prévisions Financières, 2019. «Le secteur agricole marocaine: Tendances structurelles, enjeux et perspectives de développement». 
[3] Moussaoui M. Bendaoud M. Doukkali R. et Nassif F., 2003. Contribution de l'agriculture marocaine à la réduction de la pauvreté. Rapport du Module 3; Projet FAO/ROA-Maroc.

[4] Ministère de l'Agriculture, de la Pêche Maritime, Agence pour le Développement Agricole «L'AGRÉGATION AGRICOLE, édition 2016».

[5] Jordaan, H., \& Grové, B. (2013). Transaction cost analysis of raisins marketing by emerging farmers from Eksteenskuil, South Africa. Agrekon, 52 (4), 21-42.

[6] Thomassen, K., Vassbo, S., Solheim-Kile, E., \& Lohne, J. (2016). Public-private partnership: Transaction costs of tendering. Procedia Computer Science, 100, 818-825.

[7] Williamson, O. E. (1989). Transaction cost economics. Handbook of industrial organization, 1, 135-182.

[8] Gilo, D., \& Porat, A. (2005). The hidden roles of boilerplate and standard-form contracts: Strategic imposition of transaction costs, segmentation of consumers, and anticompetitive effects. Mich. L. Rev., 104, 983.

[9] MacLeod, W. B. (2006). Reputations, relationships and the enforcement of incomplete contracts. Ton, G., Vellema, W., Desiere, S., Weituschat, S., \& D'Haese, M. (2018). Contract farming for improving smallholder incomes: What can we learn from effectiveness studies?. World Development, 104, 46-64.

[10] Bellemare, M. F., \& Novak, L. (2017). Contract farming and food security. American Journal of Agricultural Economics, 99 (2), 357-378.

[11] Maertens, M., \& Velde, K. V. (2017). Contract-farming in staple food chains: the case of rice in Benin. World Development, 95, 73-87.

[12] Reardon, T., Barrett, C. B., Berdegué, J. A., \& Swinnen, J. F. (2009). Agrifood industry transformation and small farmers in developing countries. World development, 37 (11), 1717 1727.

[13] Barrett, C. B., Bachke, M. E., Bellemare, M. F., Michelson, H. C., Narayanan, S., \& Walker, T. F. (2012). Smallholder participation in contract farming: comparative evidence from five countries. World Development, 40 (4), 715-730.

[14] Butterwick, M. (1975). Vertical integration and the use of contracts in agriculture. IV. Synopsis. Internal information on agriculture 145, April 1975. VI/1590/75-E.

[15] Eaton, C., \& Shepherd, A. (2001). Contract farming: partnerships for growth (No. 145). Food \& Agriculture Org.

[16] Abebe, G. K., Bijman, J., Kemp, R., Omta, O., \& Tsegaye, A. (2013). Contract farming configuration: Smallholders' preferences for contract design attributes. Food Policy, 40, 1424.

[17] Oya, C. (2012). Contract farming in sub-Saharan Africa: A survey of approaches, debates and issues. Journal of Agrarian Change, 12 (1), 1-33.
[18] Adjognon, S. G., Liverpool-Tasie, L. S. O., \& Reardon, T. A. (2017). Agricultural input credit in Sub-Saharan Africa: Telling myth from facts. Food Policy, 67, 93-105.

[19] Glover, D. J. (1987). Increasing the benefits to smallholders from contract farming: Problems for farmers' organizations and policy makers. World Development, 15 (4), 441-448.

[20] Minot, N., \& Ronchi, L. (2015). Contract farming: Risks and benefits of partnership between farmers and firms.

[21] Pultrone, C. (2012). An overview of contract farming: legal issues and challenges. Uniform Law Review-Revue de droit uniforme, 17 (1-2), 263-289.

[22] MAPM. (2011). Plan Maroc Vert- Nouvelle stratégie de développement des filières de production. DDFP. Paris.

[23] ONICL. (2018, 09 http://www.onicl.org.ma/portail/situation-dumarch\%C3\%A9/statistiques. Consulté le 09 2018, sur http://www.onicl.org.ma: http://www.onicl.org.ma/portail/situation-dumarch $\% \mathrm{C} 3 \% \mathrm{~A} 9 /$ statistiques.

[24] FAO. (2018, 09 20). Consulté, sur http://www.fao.org/giews/countrybrief/country.jsp?code=MA R.

[25] ONICL. (2015) CONTRAT PROGRAMMEPOUR LA FILIÈRE CEREALIERE http://www.onicl.org.ma/portail/sites/default/files/FichierPage/ CPCereales.pdf.

[26] Bouichou E. H. A Fadlaoui, K Allali, and R Arrach. Contract Farming Within the Green Morocco Plan: Case of Cereal Sector. AMAS Conference IV May 9-11, 2018 Agropolis, Meknes.

[27] Phillip L. Kunkel, Jeffrey A. Peterson, Jessica A. Mitchell. (2009). Agricultural Production Contracts: Regents of the University of Minnesota.

[28] Widyarini, M., Simatuoang, T. M., \& Engelseth, P. (2016). Social interaction and price transmission in multi-tier food supply chains. Journal of Operations and Supply Chain Management, 9 (1), 110-128.

[29] Goodhue, R. E., \& Hoffmann, S. (2006). Reading the fine print in agricultural contracts: conventional contract clauses, risks and returns. American Journal of Agricultural Economics, 88 (5), 1237-1243.

[30] Glover, D., \& Kusterer, K. (2016). Small farmers, big business: contract farming and rural development. Springer.

[31] Ramaswami, B., Singh Birthal, P., \& Joshi, P. K. (2009). Grower heterogeneity and the gains from contract farming: the case of Indian poultry. Indian Growth and Development Review, 2 (1), 56-74.

[32] Chakraborty, D. (2009). Contract farming in India: Unique solution to multilayer agricultural problems?. Review of Market Integration, 1 (1), 83-102. 